Prace Komisji Geografii Komunikacji PTG Transport Geography Papers of Polish Geographica

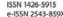
$21(4) / 2018$

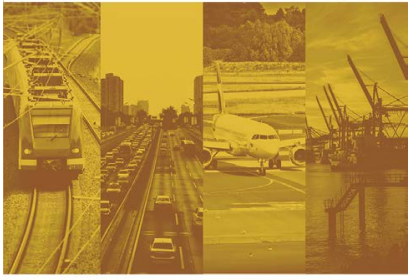
Transport Geography Papers of Polish Geographical Society

2018, 21(4), 73-79

DOI 10.4467/2543859XPKG.18.024.10782
Received: 01.12.2018

Accepted: 21.12 .2018

Published: 29.12.2018

\title{
URBAN MOBILITY: QUID HOC FACERE?
}

\section{Mobilnośc miejska: quid hoc facere?}

\section{Sergey Tarkhov}

Institute of Geography, Russian Academy of Sciences, Staromonetniy pereulok 29, 119017 Moscow, Russia

E-mail: tram.tarkhov@gmail.com

\section{Citation:}

Tarkhov S., 2018, Urban mobility: quid hoc facere?, Prace Komisji Geografii Komunikacji PTG, 21(4), 73-79.

Growth of car number (in million) in the world is continuing non-stop: $1950-67,1982-441,2006-927$, $2014-1.236,2035-2.000$ (forecast), $2050-2.500$ (forecast). 7 developed countries have $51 \%$ of world's its number (in million): USA - 250 (2010), China - 172 (2015; 205 in 2017), Russia - 51 (2014), Germany - 47 (2013), Japan - 40 (2013), France - 38 (2013), UK - 30 (2013).

Motorization is continuing even after overcoming a seeming limit at 500-650 cars per 1,000 inhabitants (average for the world is 250): Italy - 673, France - 598, Germany - 554. The big geographical distinctions exist inside each country: region Seine et Marne - 530 and Paris - 330 in France; Wyoming - 1,400, California -774 , New York state -536 in the U.S.A.
But the motorization level in some countries is higher, and overcomes 800 cars per 1,000 inhabitants: Monaco - 863, the U.S.A. - 809, Iceland - 767, Luxembourg - 747, New Zealand - 733, Qatar - 724. And some less populated mountainous states of the U.S.A. have this level much higher: $1,100-1,400$ cars per 1,000 inhabitants (Wyoming - 1405).

The motorization level in Russia is still too low: 138 (2000); 233 (2009); 303 (2015). But some Russian regions have the European level: Primorskiy kray 572 (2014), Kamchatskiy kray - 438, Moscow - only 311 (400 in 2017). 


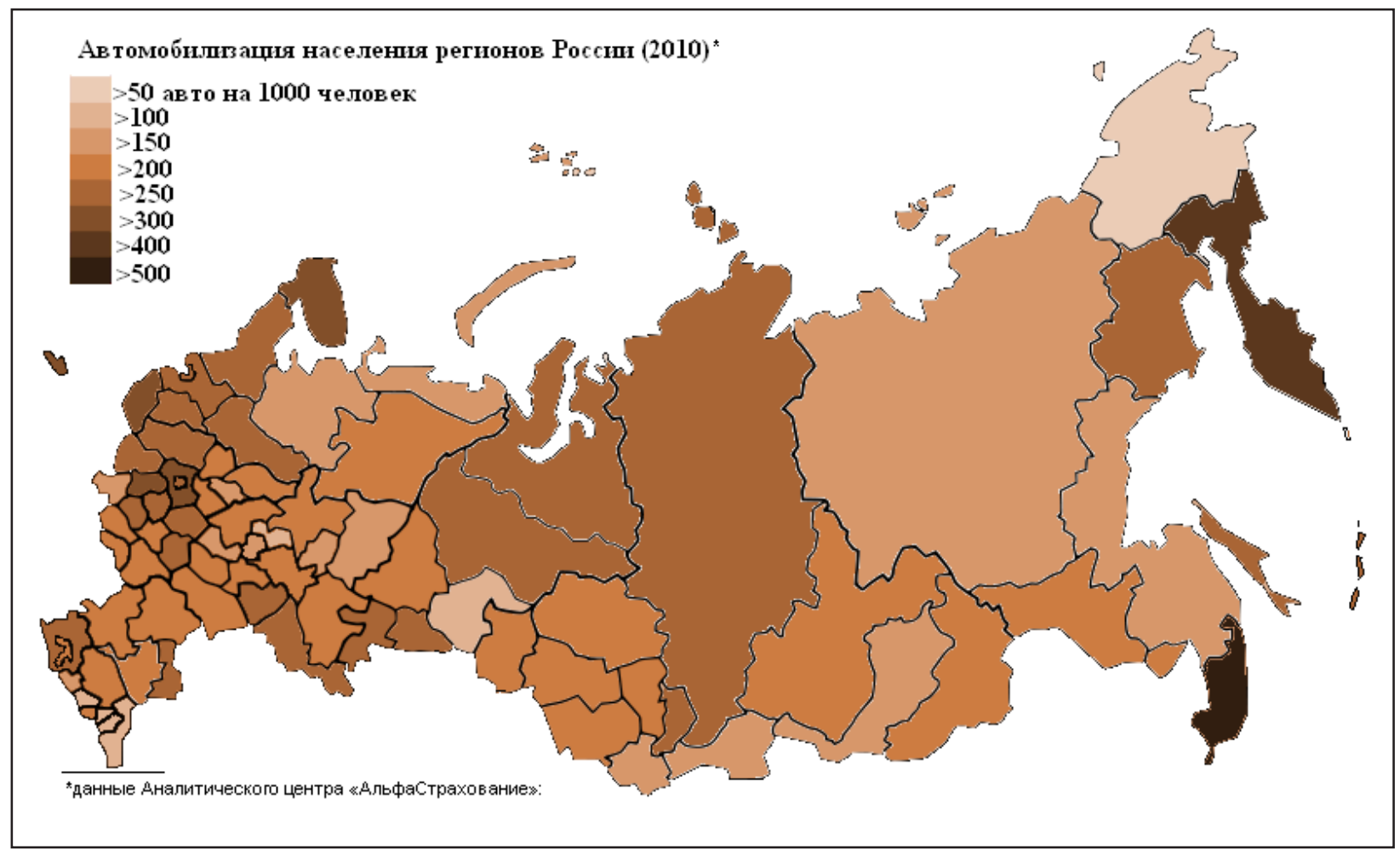

Fig.1. Level of motorization of Russian regions in 2010

Source: data from Analytic Centre "AlfaStrakhovanie".

China has very low motorization level at 126 cars per 1,000 inhabitants (2015), but in the biggest cities it is equal $300-350$.

Negative consequences of motorization. Rapid motorization created many economic, social, ecological, psychological, mental, and transportation problems in the big cities, such as strong traffic jams (congestions); capacity shortage of road network; lack of parking places for cars; noise increasing; urban environment's pollution; increasing of car and road accident's number; psychological stress of drivers and inhabitants along the streets and roads with very intensive traffic; dissolution of the traditional urban space and its transformation from continuous into dotty-linear one; social stratification of inhabitants who possess the cars and who have not it; dominance of car' mentality and lifestyle.

Traffic congestion - the main urban problem. Road capacity of old big cities with very narrow streets and inefficient street-grid lay-out is too low and can't to adopt through it the permanently growing number of cars. This is why the traffic jams (congestions) appear. The congestion problem is almost impossible to solve by usual means.

There are at least three different approaches to estimate the losses from congestions: 1)average downtime of 1 car in the traffic jam in hours per year (month, day); 2)congestion level TomTom - surplus of journey time in traffic jam over the journey time without traffic jam (in \%); 3)cost expenses of time losses when car staying in the traffic jams ( 1 hour of downtime $=8 / 10$ Euro per 1 driver).

Average downtime of one driver in the traffic jam (hours per 1 year) was for 2010: Moscow - 127, London - 79, Paris - 70, Los Angeles - 64, Houston - 57, New York City - 53, Lille - 50, Washington, D.C. - 40. The same indicators ${ }^{1}$ in 2017 were for Los Angeles - 102 hours per year, Moscow - 91, New York City - 91, Sao Paulo - 86, London - 74, Paris - 69.

Website TomTom uses the index "congestion level" - surplus of journey time in traffic jam over the journey time without traffic jam (in \%\%). Next cities had the maximal level of this index in December, 2017 (see map on Fig. 2): 1) Mexico City - 66\%, 2) Bangkok $-61 \%$, 3) Jakarta $-58 \%$, 4) Chongqing - 52\%, 5) Bucharest $-50 \%$, 6) Istanbul $-49 \%$, 7) Chengdu $-47 \%$, 8) Rio de Janeiro - 47\%, 9) Beijing - 46\%, 10) Tainan - $46 \%$, 11) Changsha - 45\%, 12) Los Angeles - 45\%, 13) Moscow $-44 \%$.

\footnotetext{
1 http://inrix.com/scorecard/
} 


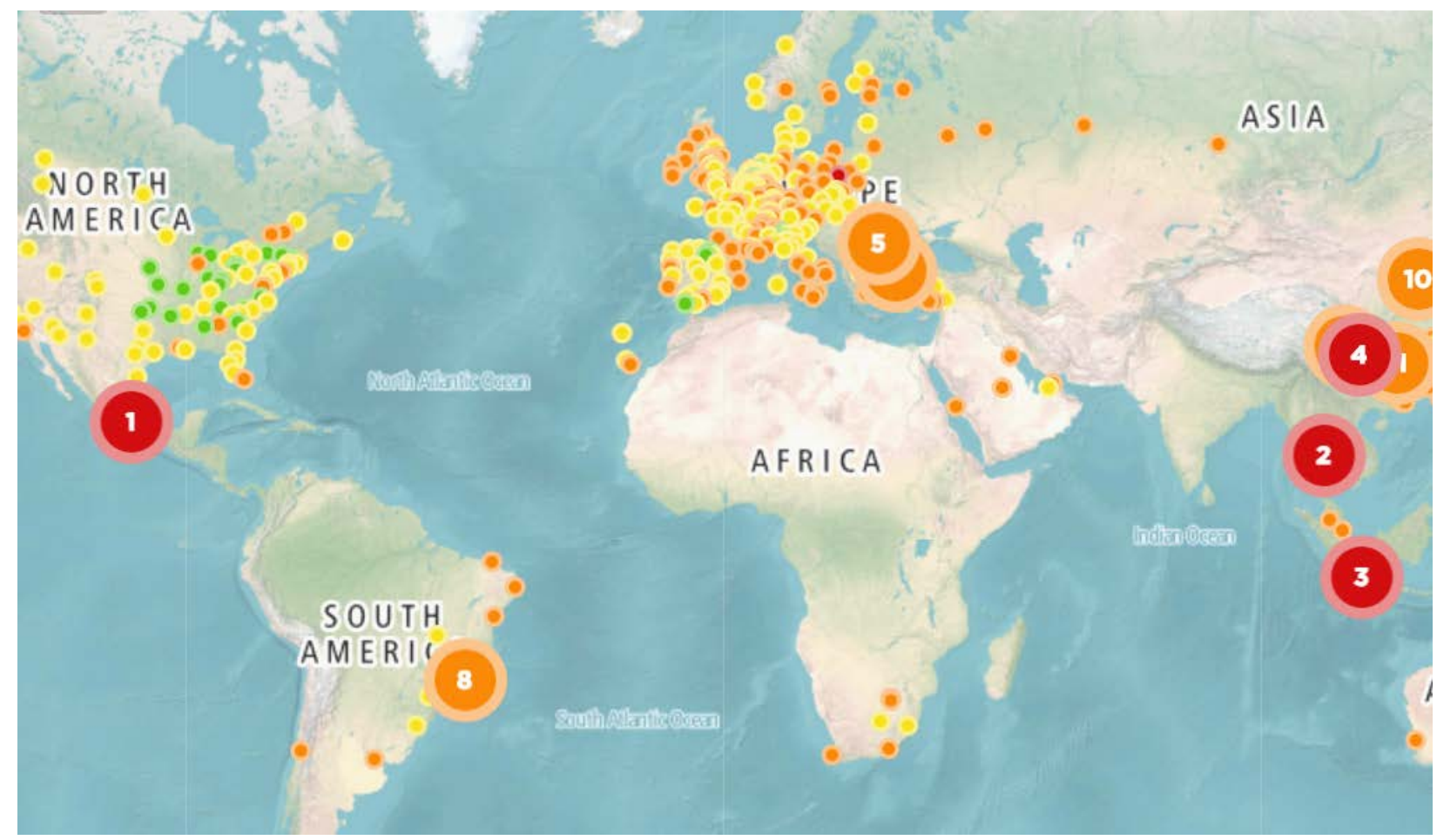

Fig.2. Congestion level TomTom for the biggest cities in December, 2017

Source: https://www.tomtom.com/en_gb/trafficindex/.

Cars staying in traffic jams in U.S. cities costed 121 billion dollars in 2011, or 5.5 billion hours. Each American driver lost 818 dollars per year, seating in the traffic jams. The dwellers of New York City had spent 8 billion dollars per year for its losses when staying in traffic jams.

Economic losses of congestion have been estimated in the United Kingdom as 2.3 billion pounds (2006), in Germany as 3 billion hours per year (1 hour of downtime $=1$ work time $=10$ Euro; it is necessary to multiply, and the losses are very big), $0.2 \%$ of general region product of lle de France (1 hour of downtime $=1$ work time $=8$ Euro).

Increasing of car number in the cities escalates the urban problems. Rapid motorization led the cities to deadlock. There are some means (remedies) to solve this edgy problem of the biggest cities, including palliative ones:

1. Construction more new expressways, bypasses, circular and tangential roads is useless way because the effect of Braes paradox: more new roads, more traffic and more traffic jams.

2. Construction and extension of network of rapid rail transit: street tramway systems, light rail transit, light and heavy subway systems, monorails, Maglev systems. This is very effective remedy. 120 new light rail transit systems have been built in cities of Europe, North America, Asia in 1980-2016 (i.e. 24 - in the U.S.A., 20 - in France, 17 - in Spain, 10 - in Turkey).
3. Development of the isolated (special) lanes only for buses (and trolley buses) or BRT (Bus Rapid Transit). First such BRT system has been opened in Curitiba (Brazil) in 1974. This remedy helps in the cities with 1-3 million inhabitants and in some areas of largest cities.

4. Carpooling - joint use of one car by 3-5 people. It is appeared in the U.S.A. during energetic crises of 1973 and 1979. Such cars are using the HOV Lane (High-occupancy vehicle lanes). Carpooling took $43.5 \%$ of all journeys and $10 \%$ all commuting trips by car in the U.S.A. in 2009.

5. Park-and-ride - introduction of limits to entrance the cars into CBD and development free parking places near suburban railway and subway stations in the outskirts of big cities, where transfer from cars is possible to rapid rail transit to get the central part of cities.

6. Telecommuting - working by Internet at home or in special computer centers near home. It is not necessary to travel from the home to the city to work and return back to home. 45 million Americans have used the telecommuting in 2006 and did not travel to the cities.

7. Creation of edge cities - the development the work and retail centers and zones outside the big cities with very developed public transit system inside and huge free parking capacities. Extrusion of the main businesses from the CBD and Downtowns to 


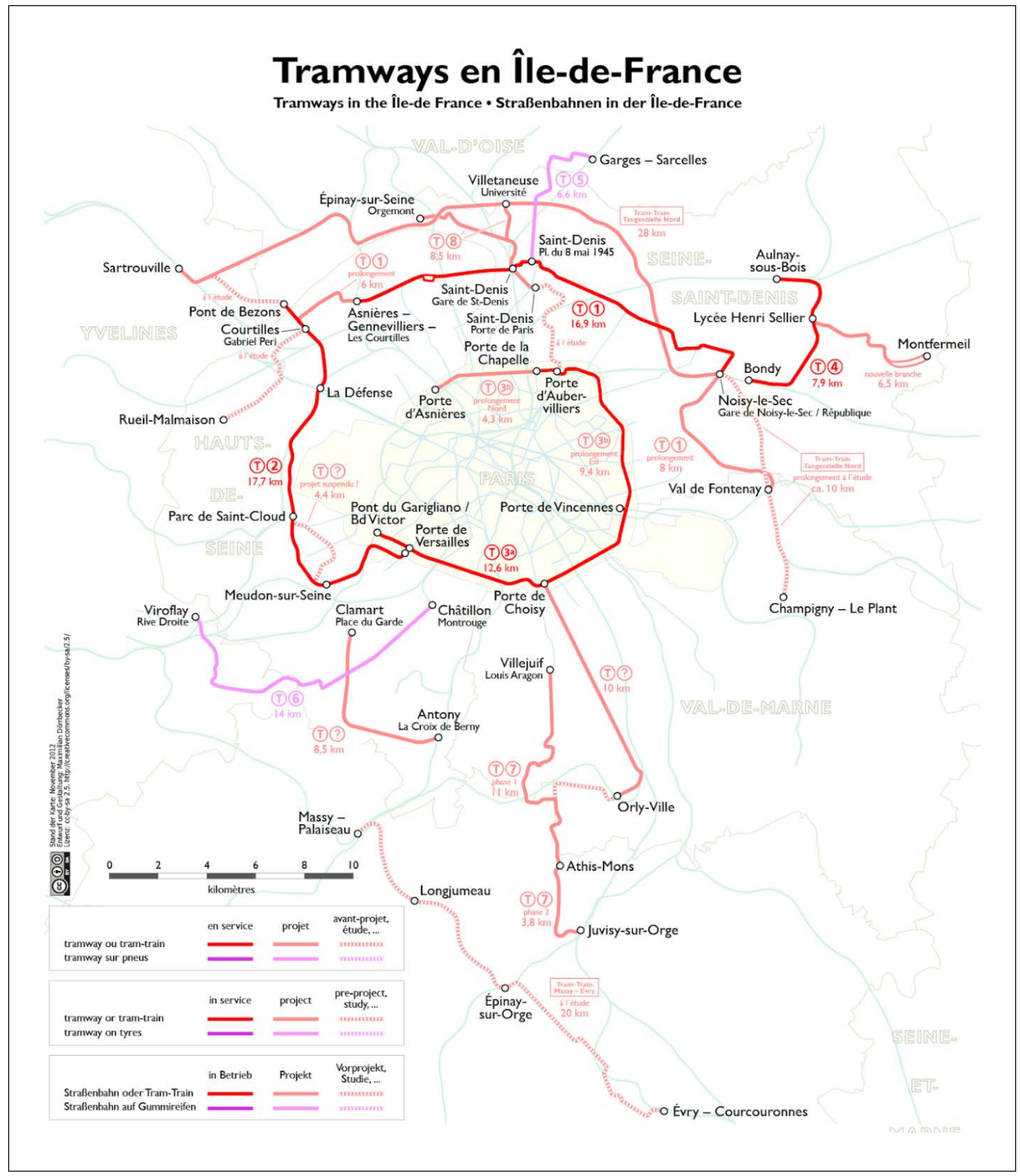

Fig. 3. Light rail transit (LRT) network in Big Paris: 10 lines (119 km) have been built in 1990-2018. The best example of LRT expansion in the world

Source: Wikipedia, author: Maximilian Dörrbecker, 2018. 
countryside, where everything is much cheaper, and there are no congestion at all.

8. Nothing to do (Russian: Ничегонеделание).

9. Congestion Charge (Road Pricing) is the best remedy to solve congestion problems. It includes 1)introducing the road pricing (congestion charge) to enter to the central parts of big city or another its parts, which is over congested; 2)introducing higher prices for parking in the central parts of the big cities. Best examples of the congestion charge's implementation are Singapore, London, Stockholm, Milano, Gothenburg, Dubai, and New York City.
Congestion charge for cars in London was introduced in February 2003 from 7.00 a.m. to 6.00 p.m. to decrease the traffic in the central areas, and it was extended to West End since 2007. Size of congestion charge has being increased ( $£$ ): February $2003-5$, July $2008-8$, January $2011-10$, June $2014-11.50$. By 2020 it would be $20 \mathrm{f}$.

Next day after its introduction the center of London have visited 190,000 cars less, then before. Only 100,000 cars drive in the center of London (30\% reduction). London drivers have paid $£ 150$ million congestion charge $+£ 51$ million as penalties in 2013/14.

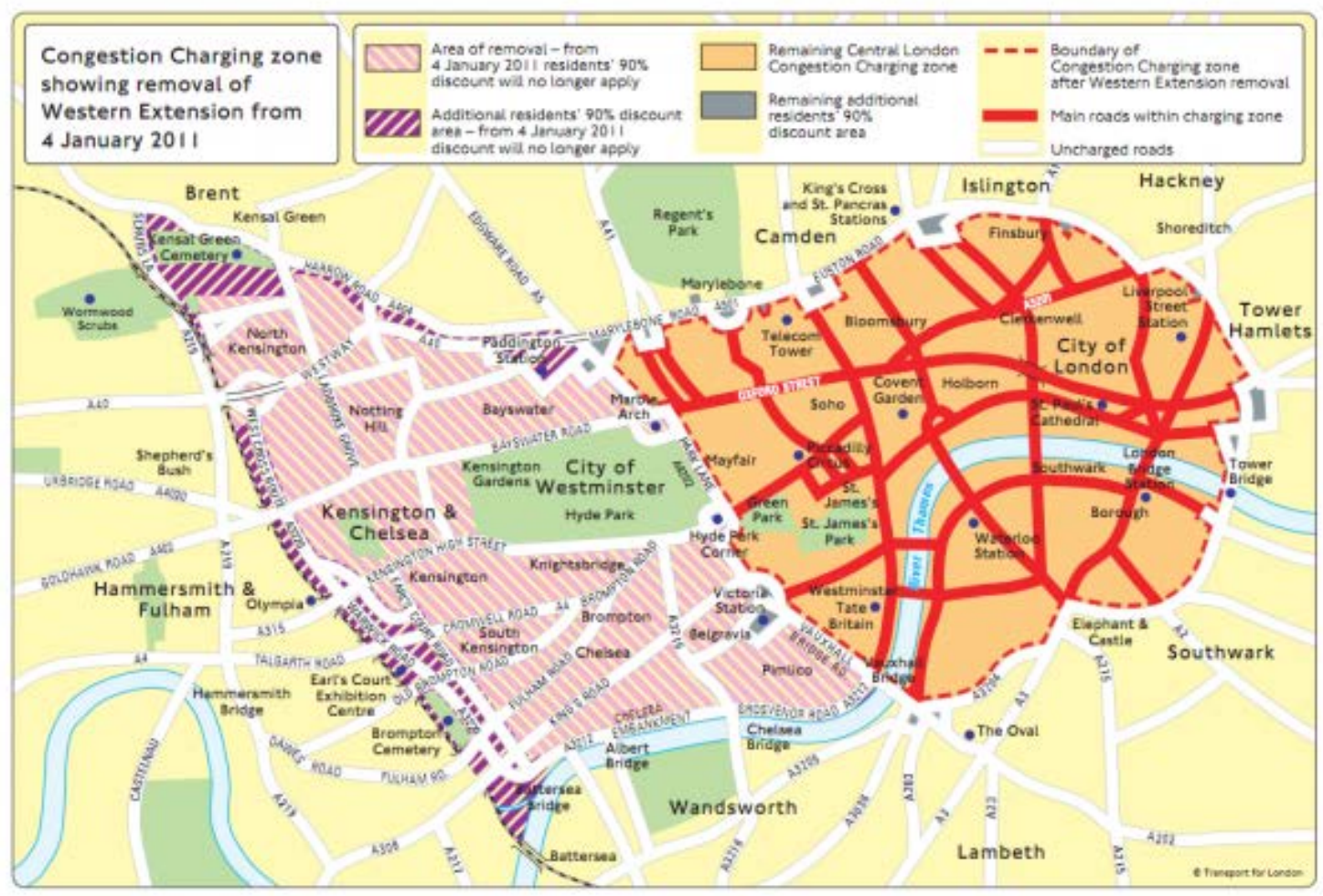

Fig. 4. London congestion charge zone

Source : Author's collection.

Electronic Road Pricing (ERP) system of electronic fee collection in Singapore has been introducing in 1998. Cars do not stop at portals EPR, because sensors read its vehicle plates and take the road fee electronically. The fee size depends on the spots and time: it is much higher in rush hours. Trip, for example, from Woodlands to Raffles Place via Yishun - CTE - CBD costs $\$ \$ 15$ (1 Singapore dollar $=0.7$ US dollar) in rush hours, when driver crosses 5 portals of ERP, but in lunch time only $S \$ 2$.

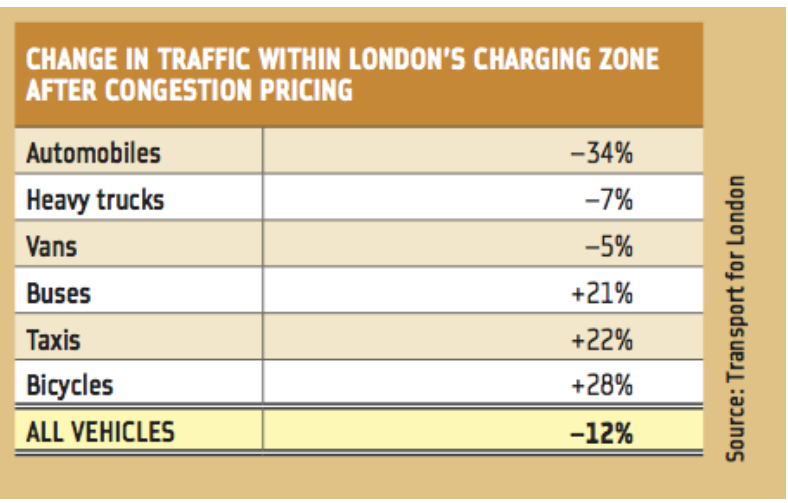

Fig. 5. The reduction of traffic in Central London after introducing of congestion charge

Source: Transport for London. 
Congestion charge in Stockholm was introduced in 2007 by entrance and exit the central area. Traffic decreased by $20 \%$.

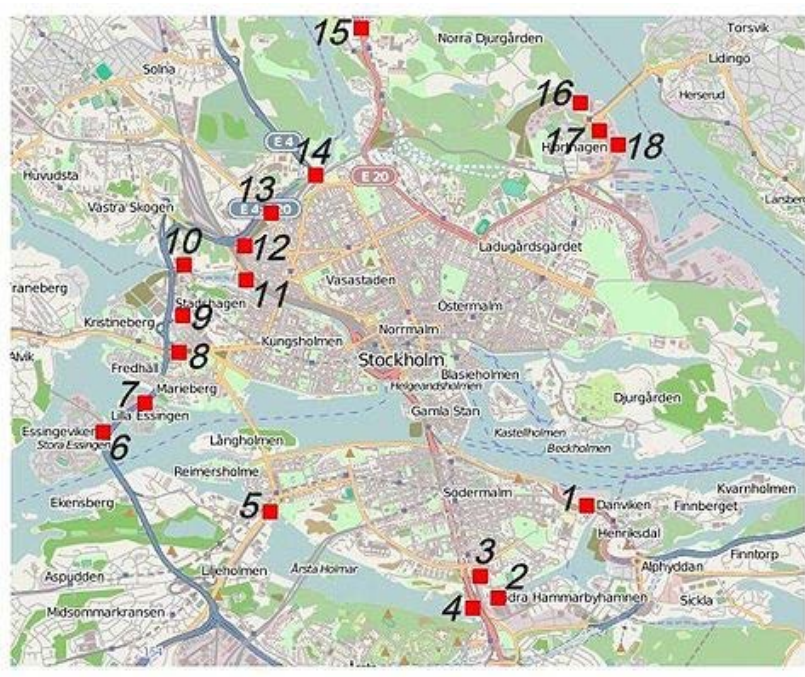

STOCKHOLMS 18 BETALSTATIONER

KÄLLA. VÄGVERKET 2005-04-25, REV. 2005-06-28

1 Danvikstull

2 Skansbron

3 Skanstullsbron

4 Johanneshovsbron

5 Liljeholmsbron

6 Stora Essingen

7 Lilla Essingen

8 Trafikplats Fredhäll

9 Trafikplats Lindhagensgatan

10 Ekelundsbron

11 Klarastrandsleden

12 Trafikplats Karlberg

13 Solnabron

14 Norrtull

15 Roslagsvägen

16 Gasverksvägen

17 Lidingövägen

18 Norra Hamnvägen

Fig. 6. Stockholm, 18 gates of congestion pricing

Source: Author's collection.

Size of congestion charge in Stockholm amounts for 00:00 a.m. to 06:29 a.m. - 0 SEK (Swedish Krone), for 06:30 - 06:59 - 10 SEK (or 1.21 EUR, 1.58 USD), for 07:00 - 07:29 - 15 SEK (1.81 EUR, 2.37 USD), for 07:30 - 08:29 a.m. - 20 SEK (2.41 EUR, 3.16 USD).
New Mayor of New York City has proposed to introduce such tax for Manhattan again in 2017. Payment was implemented since January 2018: for each car it is necessary to pay US\$11.52, for truck - US\$25.34. Taxis pay in rush hours only the extra-

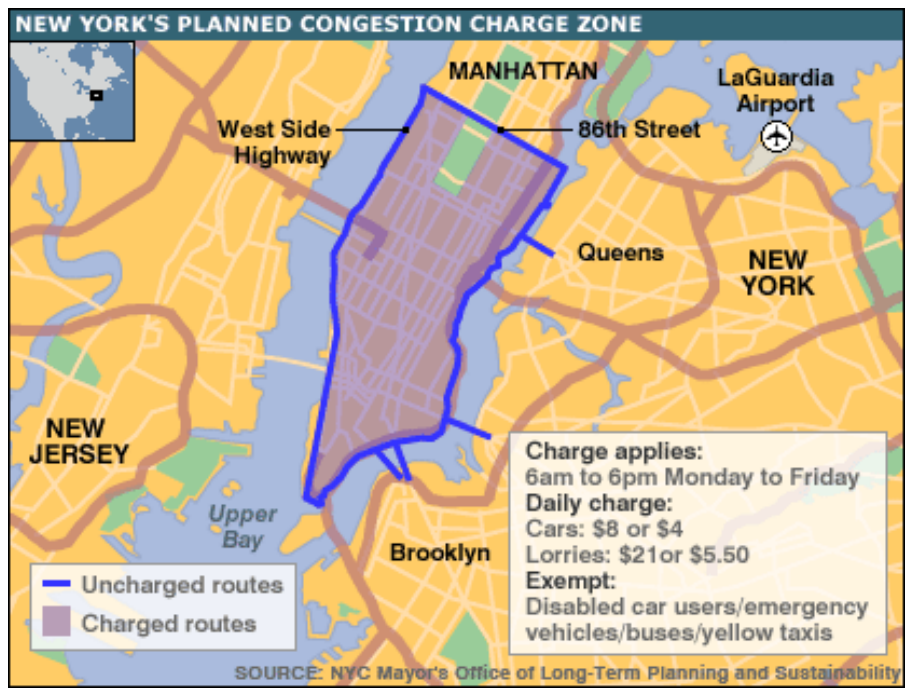

Fig. 7. Plan of introducing of congestion charge to Downtown and Midtown of Manhattan (NYC) in 2007-2008 Source: NYC Mayor's Office of Long-Term Planning and Sustainability.

Mayor of the New York City in 2007-08 has proposed to introduce the congestion charge to enter Downtown and Midtown of Manhattan from 6.00 a.m. to 6.00 p.m. (Monday - Friday) as 8 dollars for cars and 21 dollars for trucks. But the population was strongly against this proposal. charge from US\$2 to US\$5, if they drive in the central part of Manhattan south of 60th Street to Battery Park. If you drive through Brooklyn Bridge or Queensborough Bridge to FDR Drive, you pay nothing. 


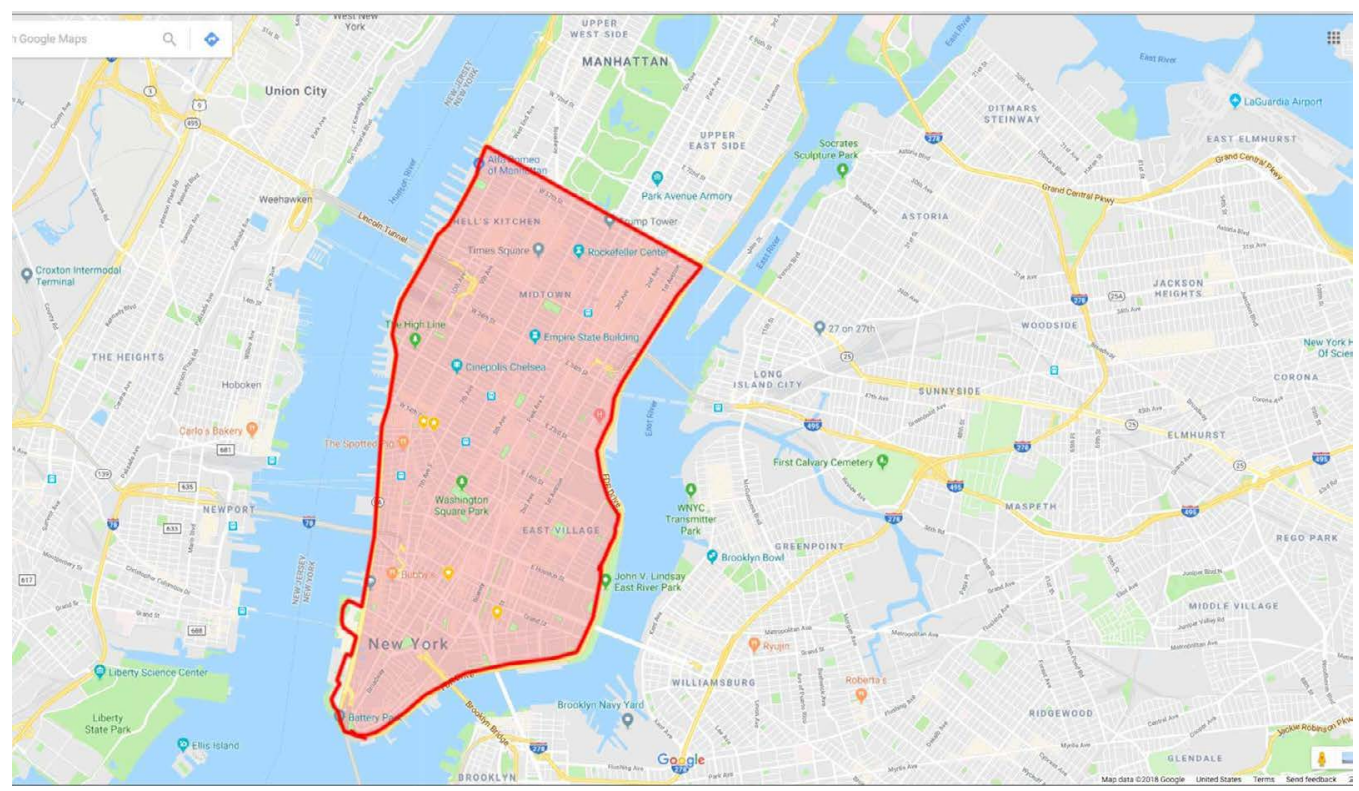

Fig. 8. Congestion charge zone in Downtown and Midtown of Manhattan (New York City) since January 2018

Source: the own elaboration of the author.

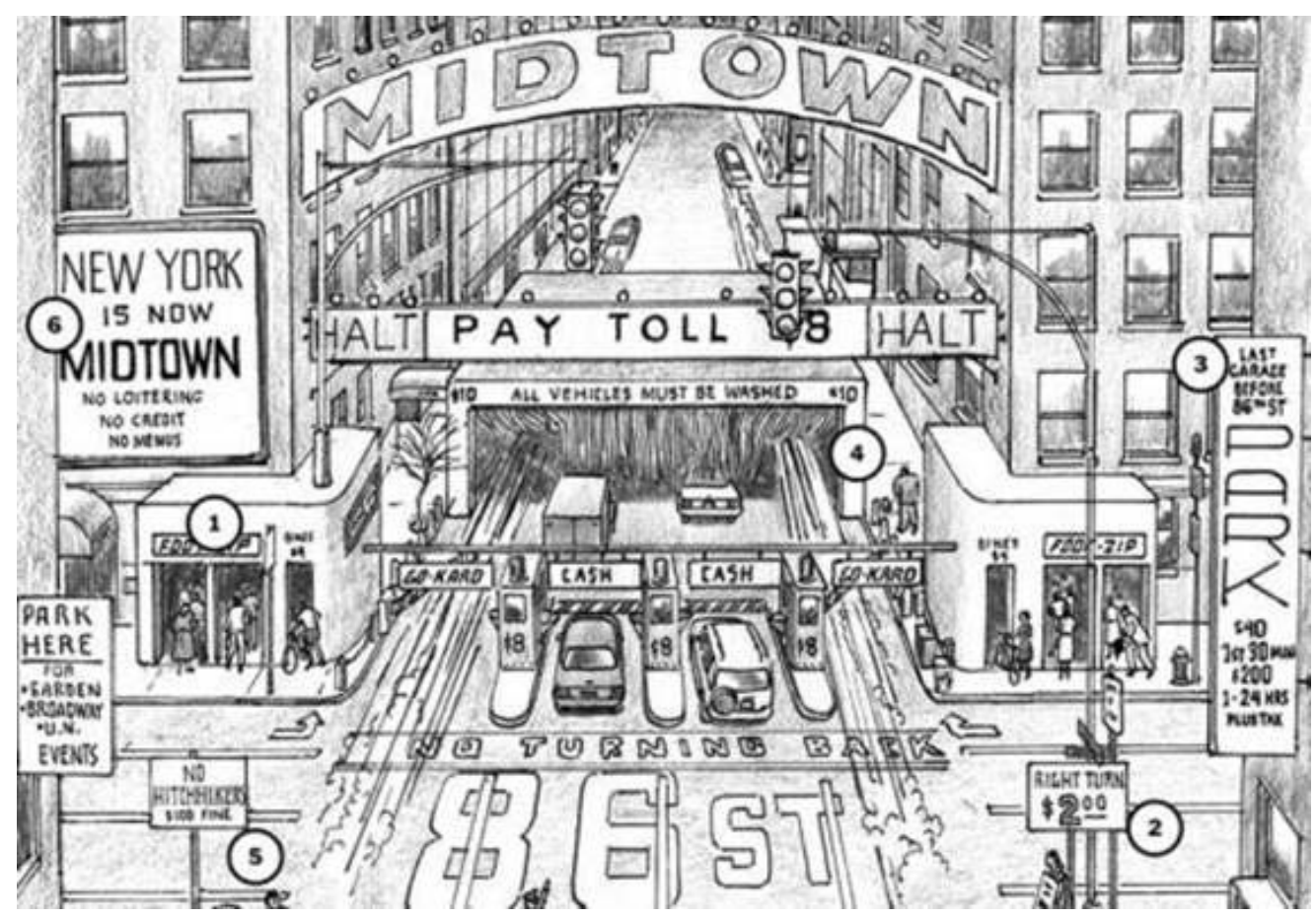

Fig. 9. Caricature of congestion charge's introduction in Midtown and Downtown of Manhattan (New York City), December 31, 2017

Source : Author's collection.

The most effective way to solve the congestion problems of big cities. The congestion charge is the only way to compensate of lost downtime in traffic jams. Cities are not rubber and could not accommo- date all cars. This is why the drivers of all cars and trucks must pay, if they need to enter to the central parts of big cities. Public transit vehicles do not have to pay for it. 